\title{
A cultura informacional na Documentação na Espanha
}

\author{
El concepto de cultura de la información en España
}

The concept of information culture in Spanish Information Science research

\section{Luana Maia WoIDA}

Faculdade de Tecnológia de Garça, Avenida Presidente Vargas, 2331 - José Ribeiro, Garça - SP - Brasil, luanamwoida@yahoo.com.br

\section{Resumen}

Este artículo identifica cómo el concepto de cultura de la información ha sido definido y abordado en la literatura científica española sobre Ciencias de la Información. Se defiende que "cultura" necesita una definición que incluya todos los elementos que influyen en el contexto sociocultural de la gestión de las organizaciones. Así, la cultura de la información se articula desde tres enfoques diferentes: la gestión, la perspectiva socioeducativa y las tecnologías de la información y la comunicación. Tales usos muestran que la cultura de la información es un contexto sociocultural que influye en el comportamiento de la gente en lo que respecta al uso y la producción de información. La revisión de la literatura científica en Ciencias de la Información ha mostrado diferencias en esta materia entre España y otros países.

Palabras clave: Cultura informacional. Gestión. Documentación. España.

\section{1. . Introdução}

A cultura é um conjunto de valores, crenças, rituais, mitos, percepções e reações de um grupo a determinados problemas e situações, e que promovem comportamentos especificos. São as convenções corretas e que perduram porque conseguem dar significado sobre como resolver problemas, inclusive os associados à informação.

Taylor (1990), citado por Cornella (1994), definiu a cultura informacional como os conhecimentos e capacidades que uma pessoa possui e que usa para atuar na sociedade atual, considerada tecnológica e informacional.

Woida (2008, apud Moraes, 2014, p. 124) explica que o termo cultura informacional começou a emergir na literatura na medida em que a informação e a cultura organizacional passaram a ser discutidas em conjunto com as tecnologias de informação e comunicação. Soares Torquato (2007) expressa semelhante entendimento.

Aparece na literatura da ciência da informação na Espanha menção ao termo cultura informa-

\begin{abstract}
This paper identifies how the concept of information culture has been defined and approched in the Spanish scientific literature on Information Science. It is defended that 'culture' needs a definition that includes all the several elements that are influential in the sociocultural context of the organization management. Thus, information culture is metioned in three different approaches: management, socio-educational and communication technology. Such uses express that information culture is a socio-cultural context that influences people behavior regarding the use and production of information. The review of the scientific literature in Information Science has showed differences in this matter between Spain and other countries.
\end{abstract}

Keywords: Information culture. Information science. Management. Spain.

cional, em relação aos temas: gestão, alfabetização informacional e formação de usuários, tecnologia de informação, comunicação. Para Woida (2008, apud Moraes, 2014, p. 124) o termo emerge a partir da década de 1990, um pouco posterior à literatura estadonidense, pois Ginman já usava o termo em 1987. Mesmo com mais de duas décadas de uso, o termo não recebeu a mesma ênfase que em países como a França e os Estados Unidos, que possuem literatura com farta discussão voltada as empresas. Percebe-se que a maturidade atingida na literatura desses países reflete-se em um conceito mais homogêneo e inclui temas da gestão. Mostram uma adaptação do conceito de cultura organizacional, porém com foco na informação, nos comportamentos informacionais, na comunicação e fluxo de informação, bem como na relação que a cultura interna de uma empresa possui com o ambiente externo. Nesse caso, é o contexto norteador e incentivador.

Parte das preocupações da cultura informacional se voltou para melhorar a gestão. Apesar de a informação ser central para a Ciência da In- 
formação, outros problemas que circundaram a organização e o acesso passam a indicar maior necessidade de participação dos indivíduos nos fluxos de informação. Martín Mejías (1998) esboçou tais preocupações na VI Jornadas Españolas de Documentación.

A necessidade de definir a cultura informacional é porque envolve muitos outros aspectos quando comparado a alfabetização. Não se trata apenas de instruir ou educar um indivíduo. Entre os autores recomendados para compreender a cultura informacional sugere-se um quadro teórico formado por Ginman (1987), Cornella (1994, 1998, 2000, 2001), Davenport e Prusak (1998), Widen-Wulff (2000), Curry e Moore (2003), Bulinge (2004), Choo et al (2006), Soares Torquato (2007), Ponjuán Dante (2007), Oliver (2008), Le Deuff (2009), Serres (2010), Comai (2011).

O objetivo desta pesquisa foi identificar como o conceito de cultura informacional é tratado pela literatura na Espanha, especificamente na abordagem da gestão. Justifica-se esse estudo porque a cultura informacional necessita de uma definição que inclua os elementos que interferem no contexto sociocultural da organização.

\section{Procedimentos metodológicos}

O estudo se fundamentou em uma revisão teórico-conceitual, realizada no acervo da Biblioteca da Universidade Carlos III de Madrid (UC3M), respaldando-se no levantamento em bases de dados disponibilizadas pela instituição, tais como Library, Information Science \& Technology e Social Sciences Citation Index (WOS). Assim, utilizou-se pesquisa bibliográfica na concepção de Lima e Mioto, 2007.

Os materiais utilizados foram periódicos, livros, anais de jornadas e eventos da Ciência da Informação publicados na Espanha e disponibilizados na UC3M. Os termos utilizados na busca foram cultura informacional e cultura de la información, ambos no idioma espanhol.

Além disso, utilizou-se o ranking Scimago Journal \& Country Rank (SJR) realizando a busca nos periódicos listados, que foram: Cybermetrics, não foi incluído pois não apresentou resultados para as palavras-chave usadas na busca; Revista Española de Documentación Científica; El Profesional de la Información; BiD - textos universitaris de biblioteconomia $i$ documentació, não foi incluída pois não apresentou resultados para as palavras-chave usadas na busca; Scire; Revista General de Información y Documentación; Ibersid; Revista Digital Sociedad de la Información; Anales de Documentación.
Não realizou-se um corte temporal para as buscas, uma vez que o volume na produção específica do tema mostra-se baixo e disperso em relação ao uso do termo cultura informacional.

\section{Apresentação, análise e discussão da literatura}

Recuperou-se um total de 58 textos publicados entre 1992 e 2014 com menção direta e indireta ao tema. Destes, 33 tratavam de temas da gestão. Em 1998 e em 2003, verifica-se maior produção de textos que mencionam o tema, coincidindo com a incorporação de modelos de gestão e das tecnologias de informação.

Apesar da revisão ter identificado três abodagens da cultura informacional, optou-se por expor neste artigo apenas os resultados referentes a abordagem da gestão, pois esta apresenta diferenças importantes em termos de desenvolvimento em comparação à literatura francesa e estadonidense. Entre as diferenças apresentadas, assinala-se a ausência de propostas de modelos e estruturação do que deve constituir a cultura informacional aplicada, com excessão do texto de Ponjuán Dante (2007). Modelos são encontrados tanto na estadonidense (Curry e Moore, 2003), na francesa (Soares Torquato,2007), e na finlandesa (Widén Wulff, 2000).

As divergências apontam para a falta de discussão sobre a origem do termo na literatura estadunidense, sendo parte da discussão francesa, como en Le Deuff (2009) ou Menou (1997). A literatura publicada na Espanha, indica a presença de atores, contexto e objetivo para a cultura informacional, como indicado no Quadro 1 em relação as abordagens tecnológicacomunicacional e sócio-educacional.

O Quadro I (na página seguinte) mostra algumas das considerações encontradas, entre as quais é possível identificar coincidências sobre quem são os atores, o contexto e os objetivos e resultados pretendidos com a cultura informacional. Além disso, percebe-se que a cultura informacional é considerada um contexto necessário. $E$, que o uso dado na literatura é plural, incluindo a participação de usuários-cidadãos como aqueles que devem ser incluídos nessa cultura, a qual em alguns casos é confundida com a cultura informática. Identificou-se que a cultura informacional associa-se aos temas de gestão da informação, do conhecimento, gestão documental, inovação, competência informacional, auditoria da informação, capital intelectual, fluxo de informação, inteligência competitiva. Também foi possível identificar que não há consenso no uso do termo cultura informacional pela Documentação na Espanha. 


\begin{tabular}{|c|c|c|}
\hline Atores & Contexto & Objetivos/resultados \\
\hline Bibliotecários & Sociedade da informação & $\begin{array}{l}\text { Alfabetização informacional } \\
\text { Competência informacional }\end{array}$ \\
\hline Usuário-cidadão & Educação e foco no aprender a aprender & $\begin{array}{l}\text { Desenvolver capacidades e habilidades } \\
\text { informacionais } \\
\text { Formar cidadão informacional }\end{array}$ \\
\hline Usuário-trabalhador & $\begin{array}{l}\text { Acesso à informação } \\
\text { Presença de valores (culturais) que promovem o uso } \\
\text { da informação } \\
\text { Formação educativa nas Universidades }\end{array}$ & $\begin{array}{l}\text { Desenvolver a percepção crítica no cidadão } \\
\text { Promover o uso crítico da informação } \\
\text { Difundir a cultura informacional } \\
\text { Incluir os cidadãos por intermédio da educação } \\
\text { Desenvolver o consumo inteligente da informação }\end{array}$ \\
\hline
\end{tabular}

Quadro I. Síntese da cultura informacional nas abordagens tecnológica-comunicacional e socioeducacional

O mesmo ocorre na literatura francesa e brasileira. Serres (2008) explica que formação de usuários, método documentário, domínio da informação, cultura informárica, cultura informacional, cultura da informação, e information literacy não são termos equivalentes e pertencem a abordagens distintas. Sendo que o que acontece na área é justamente o uso indiscriminado do termo.

$\mathrm{Na}$ abordagem da gestão a cultura informacional é considerada como o conjunto de elementos e comportamentos associados à gestão da informação, ao seu uso, busca e à criação (Davenport e Prusak, 1998; Curry e Moore 2003; Choo et al, 2008). Trata-se dos valores, crenças, pressupostos, mitos, rituais, e processos de comunicação, de liderança e de socialização que se voltam ao manejo da informação nas organizações.

$\mathrm{Na}$ abordagem sócio-educacional, a preferência é por discutir as condições sociais e educacionais, as quais são responsáveis por criar e consolidar comportamentos, percebidos nos hábitos e nos costumes das pessoas, também denominada de cultura da informação por autores como Córdoba González (2003, p. 32). Cornella (1998) afirmou se tratar de uma instituição obrigatória para as sociedades modernas, e que além disso, os conteúdos necessários para internalizar determinados comportamentos deveriam ser ensinados nas escolas e universidades. Ferroni (2004) citado por Basulto Ruíz (2009) defende que a cultura informacional compõe parte da responsabilidade do bibliotecário, uma vez que trata de inclusão por meio da educação/ formação dos usuários, corroborando com o que afirmou Gómez Hernandez (2008).

$\mathrm{Na}$ abordagem tecnológica-comunicacional, as tecnologias de informação e comunicação foram incorporadas há algumas décadas pela Documentação/ Ciência da Informação, perfazendo problemas e soluções de ordem técnica e humana, intensificando-se a partir da década de 1990. Assim, o contexto das intranets, do espaço digital e da cibercultura circundam as discussões da abordagem tecnológica-comunicacional. Cornella (2001) se refere à cultura de intercâmbio como um dos mecanismos facilitadores do fluxo de informação. Sanz Martos e Reig Hernández (2013) corroboram para a compreensão de que a cultura informacional não é equivalente à cultura informática, mas pode utilizar as tecnologias de informação e comunicação para construir um ambiente que é ao mesmo tempo social e virtual para acessar, armazenar e disseminar informação.

A cultura informacional apareceu em diferentes temas vinculados à gestão na Ciência da Informação. Cada um dos parágrafos seguintes indica a forma como o tema é tratato por diferentes aspectos da gestão. O quadro 2 indica os nomes dos autores e os temas associados à gestão, a partir dos quais extraiu-se a análise, portanto, constituindo parte do referencial teórico usado para a análise e discussão.

\begin{tabular}{lll}
\hline Autore (ordem alfabética) & Tema central na Gestão & Tema Especifico \\
\hline Alòs Moner (2003) & Mapas mentais & $\begin{array}{l}\text { Conhecimento nas organizações } \\
\text { Produção, compartilhamento e uso } \\
\text { A cultura deve sofrer mudanças } \\
\text { O comportamento reflete a cultura }\end{array}$ \\
\hline Andreu i Daufí (1998) & & $\begin{array}{l}\text { Resistências culturais } \\
\text { Identidade da instituição }\end{array}$ \\
\hline Ángel del Saz (2001) & Gestão de Documento & Administrativo \\
& Gestão do Conhecimento & $\begin{array}{l}\text { Falta de confiança } \\
\text { Melhorar o ambiente de conhecimento (produção e uso) } \\
\text { incentivo ao compartilhamento }\end{array}$ \\
\hline
\end{tabular}




\begin{tabular}{|c|c|c|}
\hline Bejarano Rojas (1998) & Gestão da Informação & $\begin{array}{l}\text { Coleta, distribuição e necessidades } \\
\text { Integração da organização } \\
\text { Valorização da informação }\end{array}$ \\
\hline $\begin{array}{l}\text { Bustelo Ruesta e García Morales Huidobro } \\
(2000)\end{array}$ & Consultoria informacional & $\begin{array}{l}\text { Determinação de hábitos de uso da informação } \\
\text { Influencia comportamentos }\end{array}$ \\
\hline Cerdá e Torrent Sellens (2014) & Inovação & Mudança \\
\hline $\begin{array}{l}\text { Claver Cortés, Llopis Taverner, González } \\
\text { Ramíres (2000) }\end{array}$ & Gestão da Informação & $\begin{array}{l}\text { Mudança cultural } \\
\text { Da cultura informática para a cultura informacional }\end{array}$ \\
\hline Comai (2011) & Inteligência competitiva & $\begin{array}{l}\text { Cultura empresarial própria } \\
\text { Estímulo a comportamentos } \\
\text { Interpretação da Informação } \\
\text { Encoraja comportamentos } \\
\text { Gestão de mudança cultural }\end{array}$ \\
\hline Cornella (1994), (1998), (2000) & Gestão da Informação & $\begin{array}{l}\text { Infonomista: veiculador, editor, organizador, dinamizador da } \\
\text { culturais } \\
\text { gestor do conhecimento e do capital intelectual }\end{array}$ \\
\hline Esteban Navarro e Navarro Bonilla (2003) & Inteligência competitiva & Valores culturais \\
\hline Ferrer (2008) & Inovação & Valorizar a informação financeiramente \\
\hline García Alsina e Ortoll Espinet (2012) & Inteligência competitiva & $\begin{array}{l}\text { Exposição à informação } \\
\text { Percepções pessoais } \\
\text { Uso de fontes de informação pessoais } \\
\text { Valores, crenças, normas interferem na Inteligência competitiva } \\
\text { Percepção de líderes sobre a informação } \\
\text { Atenção sobre a informação distorcida } \\
\text { Construção de conhecimento e tomada de decisão }\end{array}$ \\
\hline García e Fadel (2010, p. 215) & Fluxos informacionais & Manutenção de valores e crenças pelo fluxo de informação \\
\hline Mantín Mejía (2006) & Gestão do conhecimento & Mudanças culturais \\
\hline Martín Mejía (1998) & Fluxo de informação & Participação e compartilhamento \\
\hline Martínez Cerdá e Torrent Sellens (2014) & Inovação & $\begin{array}{l}\text { Alfabetização midiática } \\
\text { Uso das TICs para compartilhar e comunicar } \\
\text { Saber interpretar a informação } \\
\text { Formação do trabalhador }\end{array}$ \\
\hline Mesa redonda (1999) por Rodríguez Rovira & Gestão do conhecimento & $\begin{array}{l}\text { Novas teorias de Recursos Humanos } \\
\text { Criatividade } \\
\text { Participação }\end{array}$ \\
\hline Mesa redonda (1999), Martín Mejías & Gestão do conhecimento & Colaboração da pessoas \\
\hline Moraes e Fadel (2008) & Gestão da informação & $\begin{array}{l}\text { Manejo de informação } \\
\text { Conhecimento das pessoas }\end{array}$ \\
\hline Muñoz Cañavate (2009) & Inovação & Uso da informação \\
\hline Ortoll Espinet, 2004 & Alfabetização informacional & $\begin{array}{l}\text { Competência } \\
\text { Desempenho profissional } \\
\text { Gestores são atores } \\
\text { Manejar informação } \\
\text { Recursos e uso da informação }\end{array}$ \\
\hline $\begin{array}{l}\text { Pinto Prieto, Becerra Ardila e Gómez Flórez } \\
\text { (2012) }\end{array}$ & Gestão do conhecimento & $\begin{array}{l}\text { Cultura de intercâmbio de conhecimentos } \\
\text { Sistema de Gestão do Conhecimento } \\
\text { Mudança de comportamentos } \\
\text { Visão holística e sistêmica } \\
\text { As tecnologias não centralizam a solução }\end{array}$ \\
\hline Postigo, 2001 & Inteligência Competitiva & $\begin{array}{l}\text { Cultura é obstáculo } \\
\text { Comunicação para compartilhar informação }\end{array}$ \\
\hline Rueda Martínez & Gestão da Informação & $\begin{array}{l}\text { Desenho do sistema de informação assegura a transferência de } \\
\text { informação }\end{array}$ \\
\hline Sánchez Nistal em Mesa redonda (1999) & Gestão do Conhecimento & $\begin{array}{l}\text { Cultura dos dirigentes } \\
\text { Percepção negativa sobre informações advindas de níveis } \\
\text { hierárquicos inferiores } \\
\text { Acesso ao conhecimentos } \\
\text { Transmissão } \\
\text { Mudança cultural }\end{array}$ \\
\hline Serrano González e Zapata Lluch (2003) & Auditoria da Informação & $\begin{array}{l}\text { Melhora da qualidade } \\
\text { Conhecer o comportamento } \\
\text { Gestão do conhecimento }\end{array}$ \\
\hline Soy I Aumatell, 2003 & Auditoria da informação & $\begin{array}{l}\text { Gestão da informação } \\
\text { Mapeamento da informação } \\
\text { Uso da informação } \\
\text { Diagnóstico da cultura }\end{array}$ \\
\hline
\end{tabular}




\begin{tabular}{lll}
\hline Tapial Arregui (2003) & Gestão do conhecimento & $\begin{array}{l}\text { Uso de TIC } \\
\text { Necessidade de um departamento de Recursos Humanos } \\
\text { Barreiras humanas à implantação de G.C. }\end{array}$ \\
\hline Tena Millán e Comai (2001) & Inteligência competitiva & As mudanças devem repercutir no comportamento das pessoas \\
\hline $\begin{array}{lll}\text { Tramullas, Sánchez Casabón e Garrido } \\
\text { Picazo (2009 }\end{array}$ & Gestão da informação & $\begin{array}{l}\text { Comportamento } \\
\text { Contexto de tarefas } \\
\text { Ambientes } \\
\text { Uso de TIC }\end{array}$ \\
& & Entorno cognitivo \\
\hline Urbina Criado (2003) & Capital Intelectual & Vantagem competitiva \\
& & Gestão do conhecimento \\
\hline Valentim (2009) & Fluxo de informação & Ambientes informacionais \\
& & Estrutura organizacional \\
\hline Vásquez Rizo e Gabalán Coello (2011) & Gestão do conhecimento & Competências \\
& & Melhora da interação \\
& & Transferência de conhecimento \\
\hline
\end{tabular}

Quadro II. Autores que mencionam a cultura informacional em temas específicos da abordagem da gestão

Um resumo das ideias recolhidas sobre a cultura informacional mostra que, no que diz respeito a sua menção como contexto na gestão documental, a cultura informacional interfere no nível de consumo de serviços de informação; prevê movimentos de resistência aos valores, crenças e rituais; determina os hábitos de uso da informação e, interfere nas políticas de recursos humanos e de gestão do conhecimento e que contribuem à gestão documental. Conforme constatado na literatura, não existe uma cultura informacional adequada aos centros de documentação, sendo necessário o seu desenvolvimento.

Identificou-se que a cultura centrada no ciclo informacional se constitui determinante para a aplicação de modelos e processos, bem como considera-se que interfere no desenvolvimento de competência informacional. Também interfere nos fluxos informacionais, no registro, controle, acesso e na determinação das necessidades informacionais. Além disso, interfere no nível de consumo de serviços de informação; preve movimentos de resistência aos valores, crenças e rituais; determina os hábitos de uso da informação e, interfere nas políticas de recursos humanos e de gestão do conhecimento que se vinculam à gestão documental.

Quanto ao vínculo com o tema inovação, conclui-se que quando a cultura informacional apresenta-se insuficiente quanto aos valores, prevalece o medo de compartilhar conhecimento. $O$ desenvolvimento da consciência de que os serviços informacionais para a empresa são vitais está vinculado a essa cultura. $E$, também, que a consciência, o uso desses serviços e das bases de dados científicas são fundamentais para a inovação. Assim, o fato de a empresa acessar informação em bases de dados mediante investimento financeiro é um indicador da cultura informacional.
A cultura informacional fornece condições para o desenvolvimento de competência informacional. Além disso, não é sinônimo de cultura informática $e$, é necessário ter competências específicas para produzir e avaliar a qualidade da informação; é expressa em competências tais como ser capaz de motivar os demais membros da organização e estimular fluxos de informação; e, por fim, a cultura informacional enfatiza o uso da informação mediante padrões comportamentais que expressam competências informacionais.

$\mathrm{Na}$ auditoria da informação identificou-se que a cultura informacional é fundamental porque o comportamento informacional decorre dela, assim como por meio da auditoría da informação verifica-se que o uso da informação precisa ser feito de forma crítica, sendo resultado da cultura instalada. Mas a relação mais significativa é que por meio da auditoria da informação, pode-se conhecer a cultura informacional e identificar se esta é coerente com a empresa.

O capital intelectual, tema no qual também apareceu menção à cultura informacional, é imperativo que a cultura informacional instalada auxilie a criar e gerenciar os recursos disponíveis, promovendo e facilitando mudanças comportamentais para a adoção e uso de ferramentas tecnológicas e para criação de conhecimento.

Não se pode tocar no tema cultura informacional sem incluir os fluxos informacionais, isso porque a cultura informacional é responsável pela dinâmica desses fluxo. Este ao registrar o conhecimento organizacional contribui para preservação da cultura. Trata-se de um contexto voltado a valorizar a informação e que influencia na gestão da informação pessoal ao incentivar comportamentos de participação nos fluxos informacionais.

Quanto ao tema gestão da informação, identificou-se que a cultura instalada na organização 
pode ser um obstáculo caso não apresente valores e crenças que permitam criar uma realidade em que todos trabalham para tornar a informação um recurso acessível e compartilhado. Para obter a gestão da informação é imprescindível conhecer os tipos de informação, os fluxos de informação e a cultura informacional. Para isso, deve-se estimular o contato pessoal e a colaboração. Contudo, os próprios dirigentes de nível hierárquico superior acabam considerando que a informação valiosa não costuma advir do nível operacional, impedindo a construção de uma cultura informacional inclusiva, com fluxos informacionais que contemplem mais níveis hierárquicos. Paralelo ao desprezo pela informação advinda de camadas inferiores da estrutura, existe a indisposição dos subordinados em colaborar, a qual acaba demonstrando a ausência da cultura informacional nessa parte da estrutura, inviabilizando a participação dos indivíduos na gestão da informação. Dessa forma, a formação permanente é necessária para instruir os indivíduos para a gestão da informação.

$\mathrm{Na}$ inteligência competitiva, inclui-se a influência da cultura nacional, uma vez que existe formação/socialização e aculturação prévia à entrada na organização. A formação profissional e pessoal e a formação que recebem na organização são essencias para instigar comportamentos informacionais. Assim, a aplicação da inteligência competitiva é determinada pela cultura informacional, cuja ausência é um obstáculo para comportamentos informacionais.

Assim, deve-se considerar ao mencionar ou estudar a cultura informacional, que se trata de um contexto maior que reflete em parte da cultura organizacional, nas políticas e práticas das instituições, na promoção de mecanismos que visem o desenvolvimento e perpetuação de comportantos voltados ao manjedo da informação, bem como que espeficifique quais são os atores responsáveis por essa cultura. Por fim, é fundamental que ao tratar de cultura informacional, especificamente da abordagem da gestão, sejam incluídos os elementos que a constituem, o que significa estudar não apenas os valores, mas também as crenças, os mitos, rituais, os quais devem ser estudados nas práticas dos indivíduos.

\section{Considerações finais}

O uso do termo cultura informacional não tem homogeneidade e se vincula a diferentes temas. A menção à cultura informacional aparece em três abordagens: a que trata de temas em gestão, a abordagem socioeducacional e a relacionada a uma abordagem tecnológica-comunica- cional, sendo que estes dois ultimos não constam de maneira aprofundada no presente texto. Os distintos temas encontram harmonia em alguns pontos, sendo o principal deles que a cultura informacional é um contexto sociocultural que influencia o comportamento das pessoas em quesitos de produção e uso de informação. Assim, o tema cultura informacional na Espanha não apresenta características similares ao tratamento dado pela França e Estados Unidos, porque aborda de forma marginal o uso do termo no contexto da gestão. Por outro lado, é interessante perceber que a cultura informacional perpassa problemas envolvendo diferentes atores, determinando o contexto de percebção, produção, busca e uso da informação, bem como é fundamental para a existência de muitos outros tipos de cultura nas organizações, propciando culturas inovativas, por exemplo. Assim, não se debe deixar de considerar a cultura informacional como um contexto de influência sobre o comportamento, uma vez que mostra quais são os padrões considerados corretos e aceitos pela organização.

\section{Notas}

(1) Texto produzido do relatório de pesquisa realizada na Universidad Carlos III de Madrid, financiado com a Bolsa de Pesquisa - Exterior (Processo n. ${ }^{\circ}$ 2014/02095-1) da Fundação de Amparo à Pesquisa do Estado de São Paulo (FAPESP), de setembro de 2014 a maio de 2015

\section{Referências}

Alòs Moner, A. d. (2014). Mapas del conocimiento, com nombre y apellido. // El profesional de la información. 12:4 (jul./ago 2003) 314-318.

Andreu i Daufí, J. (1998). El perfil profesional de archivero en la organización: propuesta metodológica para el tratamiento sistémico de los recursos de información de la institución. // VI Jornadas Españolas de Documentación - FESABID. 1998

Ángel Del Saz, M. (2001). Gestión del conocimiento: pros y contras. // El profesional de la información. 10:4 (abr. 2001) $14-26$.

Basulto Ruíz, E. (2009). La alfabetización informacional. // Revista Digital Sociedad de la Información. 16 (jul. 2009) 1-32.

Bejarano Rojas, N. (1998). Los servicios de información y documentación en una empresa pública y su razón de ser en la organización. // VI Jornadas Españolas de Documentación - FESABID. 1998.

Bulinge, F. (2002). Pour une culture de l'information dans les petites et moyennes organizations: in modelo incremental d'intelligence economique. Toulon: UT, 2002. 462.

Bulinge, F. (2004). Le futur vecteur d'une culture européenne de l'information. Technologies Internationales. 102 ( mar. 2004) 37-40.

Bustelo Ruesta, C.; García-Morales Huidobro, E. (2000). La consultaría en organización de la información. // El profesional de la información. 9:9 (set., 2000) 4-10.

Choo, C. W. (2008). et al. Information culture and information use: an exploratory study of three organizations. // 
Journal of the American Society for Information Science and Technology. 5:59 (2008) 792-804.

Claver Cortés, E;; Llopis Taverner, J.; González Ramíres, M. R. (2000). El papel de la cultura informacional en la introduccion de nuevos sistemas de informacion en la empresa. // Boletin de Estudios Economicos. LV:169 (2000) 139-158.

Comai, A. (2011). Inteligencia competitiva: logros y desafíos. // El Profesional de la Información. 20:5 (set. 2011) 489493.

Córdoba González, S. (2003). La cultura de información. Ciencias de la información. // La Habana. 34:3 (dez. 2003) 31-37.

Cornella, A. (1994). El nuevo profesional de la información en la empresa. // Los recursos de información: ventaja competitiva de la empresa. Madrid: McGraw-Hill, 1994.

Cornella, A. (1998). La cultura de la información como instituición previa a la sociedad de la información. // Bibliodoc: anuari de biblioteconomia, documentació i informació. 1998.

Cornella, A. (1998). Gestión de documentos en España. // EI profesional de la información. (abr. 1998).

Cornella, Alfons (1998). Minitel: un ejemplo de la ecuación fundamental? // El profesional de la información. (abr. 1998) 1-2.

Cornella, A. (2000). El rol del infonomista. // El profesional de la información. 9:1-2 (jan./fev. 2000) 34.

Cornella, A. (2001). Sin espacio social no funciona el espacio digital. // El profesional de la información. 10:11 (nov. 2001) 32-34.

Curry, A.; Moore, C. (2003). Assessing information culture: An exploratory model. // International Journal of Information Management. 23 (2003) 91-110.

Davenport, T. H.; Prusak, L. (1998). Ecologia da Informação: por que só a tecnologia não basta para o sucesso na era da informação. São Paulo: Futura, 1998.

Esteban Navarro, M. Á.; Navarro Bonila, D. (2003). Gestión del conocimiento y servícios de inteligencia: la dimensión estratégica de la información. // El profesional de la información. 12:4 (julio-agos. 2003) 269-281.

Ferrer, A. (2008). Información en la empresa para innovar y compartir. // El profesional de la información. 17:5 (set./out. 2008) 481-486.

García Alsina, M.; Ortoll Espinet, E. (2012). La inteligencia competitiva: evolución histórica y fundamentos teóricos. Asturias: Trea, 2012.

Gendina, N. (2009). The concept of a person's information cultura: View from Russia. http://archivesic.ccsd.cnrs.fr/sic_00359475

Ginman, M (1987). Information culture and business performance. // IATUL Quarterly. 2:2 (1987) 93-106.

Gómez Hernández, J. A. (2008). Las metáforas sobre el mundo de la información y los bibliotecarios. // El profesional de la información. 17:3 (maio/jun. 2008) 340-343.

Le Deuff, O (2009). La cultura de l'information em reformation. Rennes: UR-2, 2009. Universite de Rennes 2. 532

Martín Mejías, P. (1998). De la Auditoría de Información a Intranet: Claves para la implantación de sistemas de gestión de información en las empresas. // VI Jornadas Españolas de Documentación - FESABID, 1998.

Martín Mejías, P. (2006). Gestión de la información y del conocimiento en las organizaciones. // López Yepes, José (Coord.) Manual de ciencias de la documentación. Madrid: Pirámide, 2006. 693-719.

Martínez-Cerdá, J. F.; Torrent-Sellens, J. (2014). Alfabetización mediática y co-innovavión en la microempresa: pri- meras evidencias para España. // El profesional de la información. 23:3 (maio/jun. 2014) 288-299.

Menou, M. J. (1997) Culture de l'information. In: Dictionnaire encyclopédique de l'information et de la documentation. Paris: Nathan. 167-169 (Coleção "réf.")

Mesa Redonda Sobre Gestión Del Conocimento (Llona, Eduardo; Martín Mejías, Pedro; Rodríguez Rovira, Josep M.; Saiz, Angel; Sánchez Nistal, José M.; Tascón, Jaime) (1999). // El profesional de la información. (mar. 1999).

Moraes, L. B. de; Barbosa, R. R. (2014). Cultura Informacional: um estudo em uma empresa de grande porte. II Tendências da Pesquisa Brasileira em Ciência da Informação. 7:2 (2014) 122-139.

Muñoz Cañavate, A. (2009). La información para la empresa y el sistema de $i+d+i$. El caso de la región valenciana. // Revista General de Información y Documentación. 19 (2009) 121-144.

Oliver, G. (2008). Information culture: exploration of differing values and attitudes to information in organizations. II Journal od Documentation. 64:3 (2008) 363-385.

Ortoll Espinet, E (2004). Competencias profesionales y uso de la información en el lugar de trabajo. // El profesional de la información. 13:5 (set./out., 2004).

Pinto Prieto, L. P.; Becerra Ardila, L. E.; Gómez Flórez, L. C. (2012). Carencias en los sistemas de gestión del conocimiento: una revisión bibliográfica. // El profisional de la Información. 21:3 (maio/jun. 2012) 268-276.

Ponjuán Dante, G. (2007). Gestión de información: dimensiones e implementación para el éxito organizacional. España: Trea, 2007.

Postigo, J. (2001). La inteligencia competitiva em España: una encuesta sobre siu utilización por parte de las empresas exportadoras. // El profesional de la información. 10:10 (out. 2001).

Sanz Martos, S.; Reig Hernández, D. (2013) El aprendizaje social y los profesionales de la información. // El profesional de la información. 22:6 (2013) 545-553.

Serrano González, S.; Zapata Lluch, M. (2003). Auditoria de la información, punto de partida de la gestión del conocimiento. // El profesional de la información, 12:4 (jul./agos. 2003).

Serres, A. (2008). La culture informationnelle. // Problématiques émergentes dans les sciences de l'information (sous la direction de Frabrice Papy). Lavoisier: 2008. 137-160

Soares Torquato, M. J. (2007). La culture informationnelle des PME bresiliennes: étude dans la region du grand São Paulo et proposition pour son developpement. Paris: UP-VIII. Universidade de Paris VIII, Paris, 2007. 422

Soy I Aumatell, C. (2003). La auditoria de la información, componente clave de la gestión estratégica de la información. // El profesional de la información. 12:4 (ju./ago. 2003).

Tapial Arregui, Joaquim García (2003). La gestión del conocimiento es ya una realidad para la empresa española. /I El profesional de la información. 12:3 (maio/jun., 2003).

Tena Millán, J.; Comai, A. (2001). Los propósitos de la inteligencia en la empresa competidora, cooperativa, neutral e individual. // El profesional de la información. 10:5 (maio 2001).

Tramullas, J.; Sánchez Casabón, A. I.; Garrido Picazo, P. (2009). Gestión de información personal con software para mapas conceptuales. // El profesional de la información. 18:6 (nov./dez. 2009).

Urbina Criado, M. O. (2003). Medición y auditoría del capital intelectual. // El profesional de la información. 12:4 (jul./ago., 2003). 
Valentim, M. L. P. (2009). Ambientes y flujos de información en contextos empresariales. // Ibersid. 3(2009) 55-60.

Vásquez Rizo, F; E.; Gabalán Coello, J. (2011). Implementación de un modelo de administración de capital humano en un grupo de investigación. // El profesional de la información. 20:5 (set./out. 2011).

Widen-Wulff, G. (2000). Business information culture: a qualitative study of the information culture in the Finnish insurance industry. // Information Research: An International Electronic Journal. 5:3 (2000) 1-12.
Woida, L. M.; Oliveira, E. F. T.; Valentim, M. L. P. (2010). Um estudo de coautorias na temática cultura informacional nos enancibs. Encontro nacional de pesquisa em ciência da informação, 11, 2010. Anais... http://congresso.ibict.br/index.php/xi/enancibxi/paper/vie w/58 (2106-09-20).

Enviado: 2016-03-31. Segunda versión: 2016-10-03. Aceptado: 2017-05-19. 